\title{
MAGNETIC FIELDS AND THERMODYNAMICAL CONDITIONS AT PHOTOSPHERIC LAYERS OF X17.2/4B SOLAR FLARE OF 28 OCTOBER 2003
}

\author{
V. G. Lozitsky ${ }^{1}$, E. A. Baranovsky² ${ }^{2}$ N. I. Lozitska ${ }^{1}$, V. P. Tarashchuk ${ }^{2}$ \\ ${ }^{1}$ Astronomical Observatory of the Taras Shevchenko National University, Kyiv, Ukraine, \\ ${ }^{2}$ Crimea Astrophysical Observatory, Nauchny, Crimea \\ e-mail:lozitsky@observ.univ.kiev.ua \\ (Received June 29, 2017; in final form October 02, 2017)
}

\begin{abstract}
We present the magnetic field measurements and data of semi-empirical modeling for the exclusively powerful solar flare of 28 October 2003 of X17.2/4B class, which was in active region NOAA 0486. Observations were made with the Echelle spectrograph of the horizontal solar at telescope the Astronomical Observatory of the Taras Shevchenko National University of Kyiv. Our data relate to the peak phase of the flare and to a place of the photosphere outside sunspots.

Nine spectral lines were selected for analysis, including such well known lines as FeI 5247.052,

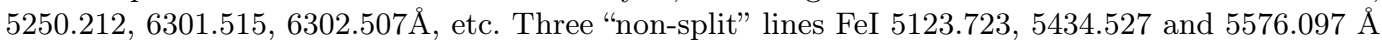
were studied too (their effective Lande factors are, in fact, $-0.013,-0.014$ and -0.012 , respectively).

Magnetic field strengths in the flare were determined by three methods: (1) by splitting of the "center of gravity" of $I \pm V$ profiles; (2) by the amplitude of Stokes $V$ profiles using "weak field approximation" and (3) using the PANDORA code, which allows to create the semi-empirical model of the flare.

We found that in the brightes places of the flare the effective magnetic field $B_{\text {eff }}$ was $0-200 \mathrm{G}$ in the middle photosphere (FeI 6302.5 and 5250.2 lines), 600-1200 G in the upper photosphere and temperature minimum zone (FeII 4923.9 and 5234.6 lines), and had $S$ polarity.

In the FeI 5434.527 line, the weak splitting of emission peaks near its core was observed; its value was $10-20 \mathrm{~m} \AA$. If this splitting is interpreted as a manifestation of the Zeeman effect, then the corresponding magnetic field is about $25-50 \mathrm{kG}$. The magnetic polarity of this "superstrong" field should be $N$, i.e. opposite to the polarity of other FeI lines with greater Lande factors.

A semi-empirical model of the flare was build with the PANDORA code, which allows to determine the magnetic field and thermodynamical conditions on both photospheric and chromospheric levels using non-LTE approximation. It was found that the magnetic field in the middle photosphere was $1000-1200 \mathrm{G}$. The temperature in the flare increased up to $1000 \mathrm{~K}$ for $\lg \tau_{5} \approx-3$. Turbulent velocity $v_{\mathrm{t}}$ is almost the same as in an undisturbed atmosphere, but in the range from $\lg \tau_{5}=1$ to $\lg \tau_{5}=-1$; from $\lg \tau_{5}=-1$ to $\lg \tau_{5}=-3$ a sharp increase $v_{\mathrm{t}}$ was found where $v_{\mathrm{t}}$ reaches about $3.5 \mathrm{~km} / \mathrm{s}$.
\end{abstract}

Key words: Sun, solar activity, solar flares, solar magnetic fields, super-flare of 28 October 2003 of X17.2/4B class, effective magnetic fields, extremely strong fields, semi-empirical model of the flare.

PACS number(s): 96.60.Hv, 96.60.Q-, 96.60.qe

\section{INTRODUCTION}

Solar flares are the most powerful and violent processes in the solar atmosphere caused by rapid transformation of magnetic energy into other forms of energy. They cover a wide range of altitudes in the atmosphere, from the photosphere to the solar corona, although the bulk of the flare energy is released in the chromosphere and corona (see, e.g., [1]). That is why magnetic field measurements at many levels of the atmosphere are highly important for understanding the physical processes that take place in the areas of the flares.

To study magnetic fields in the flares, the Echelle spectra are especially valuable because they give simultaneous recording of thousands of spectral lines formed at different heights in the solar atmosphere, with different sensitivity to temperature and to the Zeeman splitting. In principle, the Stokes measurements in a limited number of specially selected lines are valuable for this pur- pose too; such are nine lines of FeI, MgI, NaI and TiI, which are used at the space observatory Hinode [2]. However, it should be noted that the Hinode data allow to study the spectral effects in a relatively narrow wavelength range around selected magnetosensitive lines because the Fabry-Perot filter is used here as a spectral monochromator. For spectral lines FeI 6301.5 and FeI 6302.5 , this is the range about $2.4 \AA$.

Let us formulate some scientific problems that have arisen in connection with the study of magnetic fields in flares by the Echelle spectra of the photosphere and the chromosphere.

First of all, it is the problem of the upper limit of the magnetic field strength in flares. There is no full clarity in the question what exactly this upper limit is. Direct measurements of the Zeeman splitting in metalic lines with the effective Lande factors $g_{\text {eff }}$ in the range of 1.01.7 showed that the intense emission peaks form in the volumes with magnetic field till $3-4 \mathrm{kG}$ [3]. However, if 
the actual magnetic field in flares did not exceed 3-4 $\mathrm{kG}$, emission peaks in the lines like FeI 5434.5 with exceptionally low magnetic sensitivity $\left(g_{\text {eff }} \approx 0.01\right)$ should be observed as unsplit at the of noise level of $1-2 \%$, which is typical for photographical observations. In reality, the reliable splitting was observed sometimes in these "unsplit" lines; its value reaches $40 \mathrm{~m} \AA$, that corresponds to almost $100 \mathrm{kG}[4-6]$.

Another interesting issue is the problem of high-rise distribution of the magnetic field in a flare. In the quiet atmosphere, magnetic field steadily decreases with height due to decrease in gas pressure. In reality, it was shown that the magnetic field distribution versus height may be non-monotonous, with a narrow peak in the range of the upper photosphere $[3,7]$. In other flares such nonmonotonous changes were not observed [8-10]. A possible reason for this disagreement is that the character of the altitude distribution of the magnetic field in the area of a flare can depend on the phase of the development of the flare. In fact, Kurochka et al. [11] found a nonmonotonous distribution of the magnetic field at peak of a flare, which gradually changed to the usual monotonous distribution during $10 \mathrm{~min}$ of the flare evolution. Obviously, new observational data are needed here for greater clarity.

The aim of this paper is magnetic field measurements in the region of the especially powerful solar flare of $\mathrm{X} 17.2 / 4 \mathrm{~B}$ class and building of a semi-empirical model of this flare. Taking into account the power of the flare and the above-mentioned advantages of Echelle observations, it is hoped that relevant data can clarify some of the issues that are outlined above.

\section{OBSERVATIONS}

Observations were carried out with the Echelle spectrograph of the horizontal solar telescope at the Astronomical Observatory of the Taras Shevchenko National University of Kyiv [12]. This instrument can record the solar spectrum simultaneously from 3800 to $6600 \AA$ with a spectral resolution of $30 \mathrm{~m} \AA$ in the green region and space resolution 1-2 Mm. All spectra were made with ORWO WP3 photoemulsion.

The flare under study occurred on October 28, 2003 in active region NOAA 0486 and had X17.2/4B class. This active region was not very far from the disc center, the cosine of its heliocentric angle $\mu$ was 0.91 . The peak of $H_{\alpha}$ flare emission was observed in the time interval between $11^{h} 00^{m}$ and $11^{h} 10^{m}$ UT [13]. The spectra of the flare were photographed with the above-named Echelle spectrograph from $10^{h} 07^{m}$ to $11^{h} 22^{m} \mathrm{UT}$; total number of obtained Zeeman spectrograms was 18 . In the present work, the spectrogram for $11^{h} 06^{m}$ UT is studied mainly; this spectrogram corresponds to the peak phase of the flare.

According to the measurements of the GOES detectors, this flare occupies the third position in the ranking of X-ray on $\lambda=1-8 \AA$ for the entire time since 1976 [14]. It should also be noted that this active region NOAA
0486 produced the greatest (for the named period) flare of X28+ class, which originated on the western Sun's limb one week later, 4 November 2003. Less than a day after the flare of 28 October 2003 (about $18 \mathrm{hrs}$ ), the 9 rank magnetic storm arose on the Earth.

A sharp increase in the flow of high-energy protons began during the flare; the next day the flows of protons exceeded the levels of $10^{2}, 10^{3}$ and $10^{4}$ particles $\mathrm{cm}^{-2}$ $\mathrm{s}^{-1} \mathrm{sr}^{-1}$ for protons with energies of $100 \mathrm{MeV}, 50 \mathrm{MeV}$ and $10 \mathrm{MeV}$, respectively. It should be noted that for the quiet Sun the typical flow of protons is about $10^{-1}$ particles for all three energetic ranges; thus, the flow of protons increased about 3-5 orders after this flare.

This flare has been studied in other studies $[15,16]$, but for other times and, basically, in other spectral lines. In particular, Lozitsky [15] and Baranovsky et al. [16] studied this flare at the time of $11^{h} 13^{m}$ UT, i.e. after its maximum phase.

\section{SELECTED SPECTRAL LINES AND PECULIARITIES OF THEIR PROFILES}

Nine spectral lines were selected for analysis (Table). In this Table, the wavelength $\lambda$, the equivalent width of the line in the spectra of the quiet Sun, $W$, and the excitation potential of low term, $E P$, are given according to Moore et al. [17]. The effective Lande factors $g_{\text {eff }}$ of FeI lines correspond to the laboratory-determined values [18] excluding line No. 8, for which this parameter corresponds to the theoretical case for the $L S$ coupling.

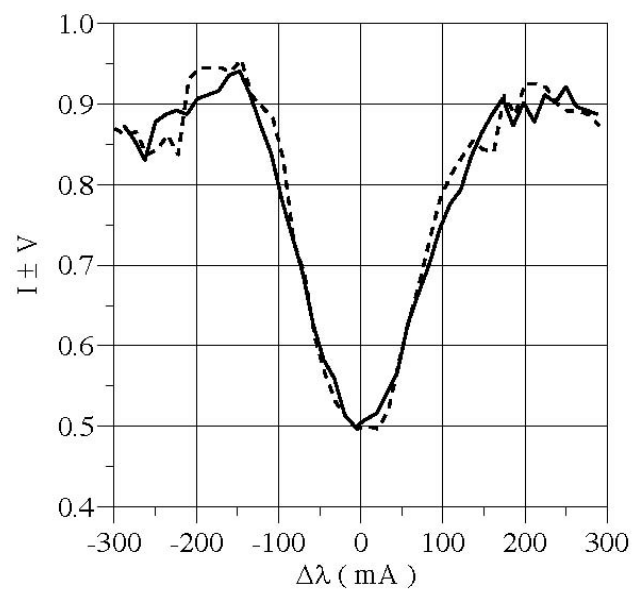

Fig. 1. The observed $I \pm V$ profiles of Fe I 5123.723 line in the flare, for $L=10$ (see Fig. 5 below).

For $11^{h} 06^{m} \mathrm{UT}$, all the FeI lines listed in Table, excluding FeI 5434.5, line have pure Fraunhofer profiles (see, for example, Fig. 1). Both FeII lines (Nos. 8 and 9 in the Table) have intensive emission peaks, which exceed the level of the nearest spectral continuum by about $30 \%$ (Fig. 2). A second obvious peculiarity of FeII profiles is the essential spectral shift of $I+V$ profiles versus $I-V$, that can indicate the existence of a very strong magnetic field in the flare volume. 


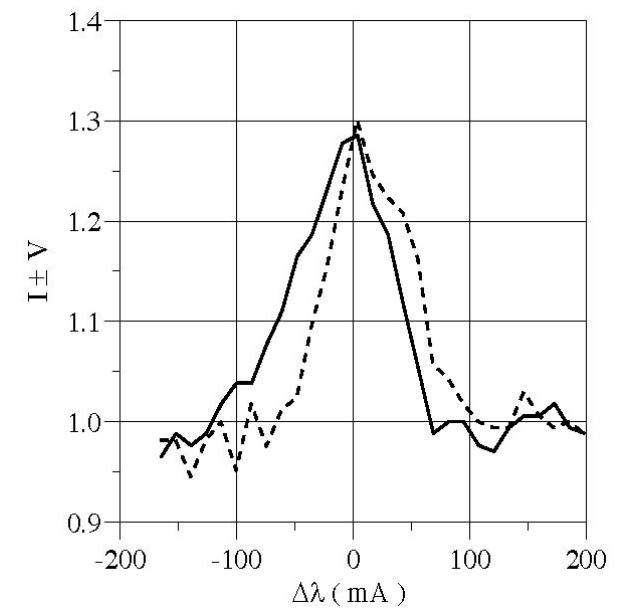

Fig. 2. $I \pm V$ profiles of FeII 5234.630 line in the flare, for $L=10$.

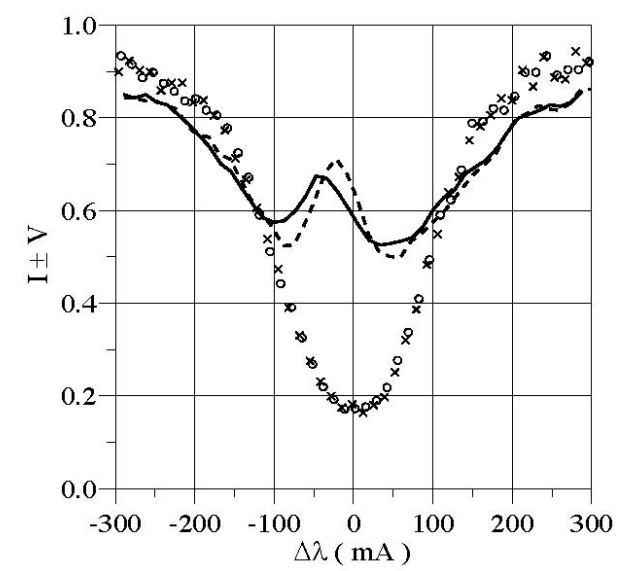

Fig. 3. Comparison of $I \pm V$ profiles of FeI 5434.5 line in the flare, for $11^{h} 14^{m}$ UT (solid and dashed lines), with such profiles of the same line outside the flare (crosses and circles). One can see the well visible shift of emissive peaks in the line core, which can indicate presence of the very strong magnetic field of $N$ polarity.

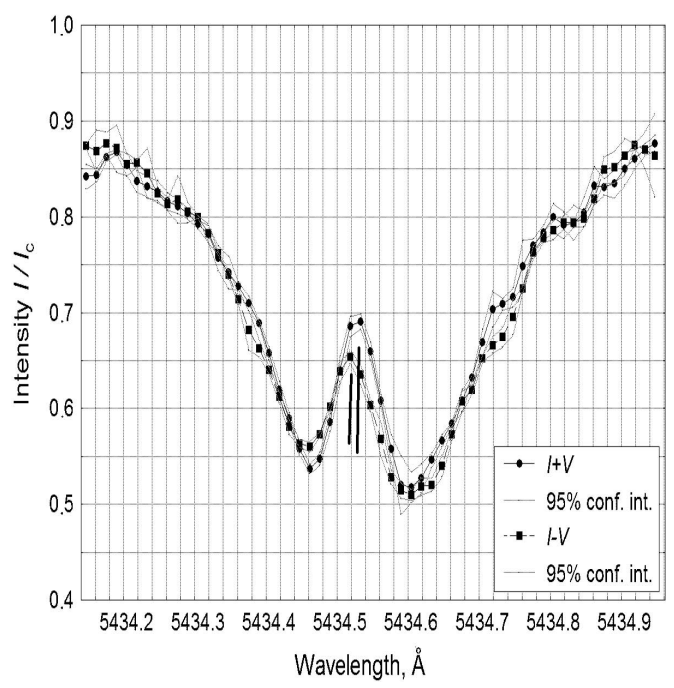

Fig. 4. The observed $I \pm V$ profiles of FeI 5434.5 line in the flare for other moment, $11^{h} 14^{m} \mathrm{UT}$, the photometrical section No-13, by the data of the thrice-repeated photometry of the same place on the spectrogram. The splitting of emissive peaks corresponds to $B=30 \pm 10 \mathrm{kG}$ here, and $N$ polarity, i.e. it is also opposite to the data by other lines (FeI 5250.2 etc.)

Fe I 5434.5 has well visible emission peaks in the flare, in its core (Figs. 3, 4). Analogous peaks are absent in the two other "non-split" lines, Fe I 5123.723 and 5576.097. It is interesting to note that emissive peaks in core of $\mathrm{Fe}$ I 5434.5 have two specific peculiarities: (i) weak splitting of about 10-20 mA, and (ii) a "violet" Doppler shift versus the Fraunhofer profile on about $40 \mathrm{~m} \AA$. The effect (i) was checked using the thrice-repeated photometry of the same place on the spectrogram, and using the averaging of the data on a large area $(5 \mathrm{Mm})$ on the Sun. Both these checkings have confirmed the reality of the above-named splitting of emissive peaks in FeI 5434.5.

\begin{tabular}{|c|c|c|c|c|c|}
\hline No. & $\begin{array}{c}\text { Element and } \\
\text { number of } \\
\text { multiplet }\end{array}$ & $\begin{array}{c}\lambda(\AA) \\
\text { Wavelength } \\
\text { width } \\
W(\mathrm{~m} \AA)\end{array}$ & $\begin{array}{c}\text { Equivalent } \\
\text { potential } \\
E P(\mathrm{eV})\end{array}$ & $\begin{array}{c}\text { Excitation } \\
\text { Lande factor } \\
g_{\text {eff }}\end{array}$ \\
\hline 1 & FeI-16 & 5123.723 & 101 & 1.01 & -0.013 \\
\hline 2 & FeI-1 & 5247.058 & 59 & 0.09 & 1.998 \\
\hline 3 & FeI-1 & 5250.216 & 62 & 0.12 & 2.999 \\
\hline 4 & FeI-15 & 5434.527 & 184 & 1.01 & -0.014 \\
\hline 5 & FeI-686 & 5576.097 & 113 & 3.43 & -0.012 \\
\hline 6 & FeI-816 & 6301.515 & 127 & 3.65 & 1.669 \\
\hline 7 & FeI-816 & 6302.507 & 83 & 3.69 & 2.487 \\
\hline 8 & FeII-42 & 4923.930 & 167 & 2.89 & 1.70 \\
\hline 9 & FeII-49 & 5234.630 & 81 & 3.22 & 0.869 \\
\hline
\end{tabular}

Table. List of spectral lines under study 


\section{EFFECTIVE MAGNETIC FIELD $B_{\text {eff }}$}

The effective magnetic field strength $B_{\text {eff }}$ was determined by splitting of the "center of gravity" of $I+V$ profiles versus $I-V$. This method allows to determine the magnetic field averaged by all the square of the entrance aperture of the instrument; this square depends, mainly, on the image vibration during observations and corresponds to about $3 \mathrm{Mm}^{2}$ in our case. For small Zeeman splitting, when the observed splitting $\left(\Delta \lambda_{H}\right)_{\text {obs }}$ is much less than half-width $\Delta \lambda_{1 / 2}$ of the spectral line, such measurements give the average longitudinal component of the magnetic field strength, i.e. $\left\langle B_{\|}\right\rangle$. If, on the contrary, $\left(\Delta \lambda_{H}\right)_{\text {obs }}>\Delta \lambda_{1 / 2}$, then such method allows to measure the average value of the magnetic field module |B|.

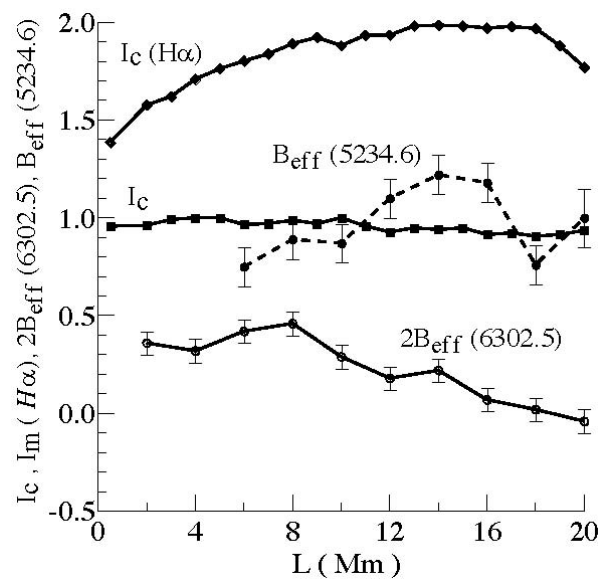

Fig. 5. Intensity in spectral continuum $I_{c}$, peak intensity in $H_{\alpha}$ vs. intensity in the nearest spectral continuum, $I_{m}\left(H_{\alpha}\right)$, and effective magnetic fields $B_{\text {eff }}(6302.5)$ and $B_{\text {eff }}(5234.6)$ in the flare along the direction of the entrance slit of the spectrograph. In this Figure, $L$ represents the corresponding positions of the separate points of the entrance slit on the Sun, in mega-meters $(\mathrm{Mm})$.

The measured values of $B_{\text {eff }}(6302.5)$ and $B_{\text {eff }}(5234.6)$ in FeI 6302.5 and FeII 5234.6 lines are given in Fig. 5 in comparison with the intensity in the spectral continuum $I_{c}$ and the peak intensity in $H_{\alpha}$ versus the intensity in the nearest spectral continuum $I_{m}\left(H_{\alpha}\right)$. Both $B_{\text {eff }}$ are presented here in kilogauss $(\mathrm{kG})$, whereas $I_{c}$ are given in arbitrary units. One can see that the enter slit of the spectrograph crossed a space of the photosphere outside sunspots, where the intensity in the spectral continuum was almost the same at different places. Despite this, emission in $H_{\alpha}$ was very strong here reaching the value about two in comparison with the nearest spectral continuum. The magnetic field in the middle photosphere, as one can see from $B_{\text {eff }}(6302.5)$, was relatively weak, in the range of 0-200 G. However, much stronger fields were measured in the upper photosphere, up to about $1.2 \mathrm{kG}$ by FeII 5234.6 line (see $B_{\text {eff }}(5234.6)$ in Fig.5). A similar strong field, up to $1 \mathrm{kG}$, was measured by the second FeII line, $\lambda=4923.930 \AA$. These results confirm the following tendency observed in other flares: $B_{\text {eff }}$ in the upper photosphere and temperature minimum zone is, as a rule, stronger than in the middle photosphere [19]. Also, it is necessary to note that the maximum of $B_{\text {eff }}$ by FeII line ( $L=14-16 \mathrm{Mm}$ in Fig. 5) approximately coincides with the peak of $H_{\alpha}$ emission of the flare $(L=13-18 \mathrm{Mm})$.

\section{STOKES $V$ IN FeI $\mathbf{5 4 3 4 . 5}$}

Magnetic field measurements by the amplitude of Stokes $V$ in a spectral magneto-sensitive line are "classical", beginning from the Babcock magnetograph [20]. Let us remember the main perculiarities of the Stokes $V$ profile for different ranges of the Zeeman splitting.

If the Zeeman splitting $\Delta \lambda_{H}$ is weak versus half-width $\Delta \lambda_{1 / 2}$ of a spectral line, i.e. $\Delta \lambda_{H} \ll \Delta \lambda_{1 / 2}$, this is the well-known regime of "weak field approximation". In this case, the Stokes $V$ amplitude is proportional to $(\partial I / \partial \lambda) \Delta \lambda_{H} \cos \gamma$, where $I$ is the Stokes $I$ parameter, $\lambda$ is wavelength, $\gamma$ is the angle between the magnetic field line and the line of sight. Thus, in this case the Stokes $V$ shape is the same as the shape of Stokes $I$ gradient $\partial I / \partial \lambda$. By varying the product $(\partial I / \partial \lambda) \Delta \lambda_{H}$, we can choose the amplitude of the parameter $(\partial I / \partial \lambda)$ to be the same as for the Stokes parameter $V$, assuming, for example, $\gamma=0^{\circ}$. This allows us to calibrate the value of Stokes $V$ in the field values (in gauss, G), i.e. to measure the magnetic field.

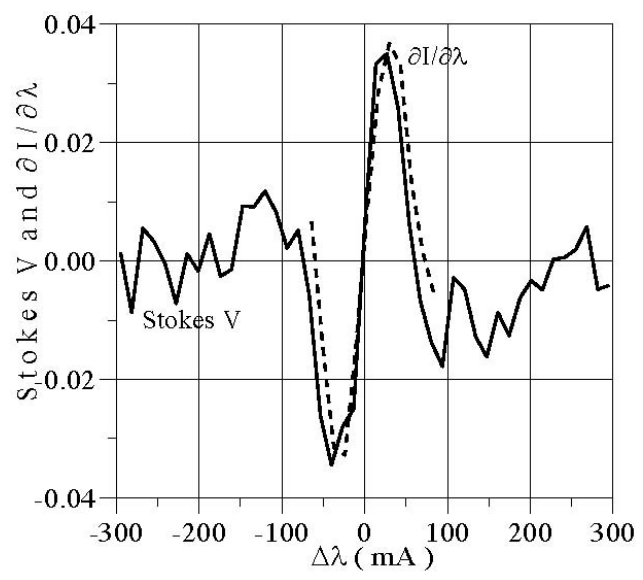

Fig. 6. Comparison of Stokes $V$ and $\partial I / \partial \lambda$ profiles of FeI 5434.5 line in the flare. The amplitude of $\partial I / \partial \lambda$ is shown for $\Delta \lambda H=10 \mathrm{~m} \AA$, which corresponds to the magnetic field strength $B=51.8 \mathrm{kG}$.

The second important peculiarity of Stokes $V$ in the case of "weak field approximation" is that Stokes $V$ peak separation $\Delta \lambda_{V}$ is almost unchanging with $\Delta \lambda_{H}$, and its value is approximately equal to $\Delta \lambda_{1 / 2}$, i.e $\Delta \lambda_{V} \approx \Delta \lambda_{1 / 2}$. This criterion allows to estimate the true half-width $\Delta \lambda_{1 / 2}$ of an emissive component in case of a complicated profile which has superposition of Fraunhofer and emissive components.

Such approach to the interpretation of the observations was applied to the data on FeI 5434.5 line (Fig. 6). On the base of of $I \pm V$ profiles, $V$ and $\partial I / \partial \lambda$ parameters were determined, and by varying of $\Delta \lambda_{H}$, the best agreement of the amplitudes of both parameters was found. 
One can see from this Figure that the observed Stokes $V$ profile has a complicated shape but with two obvious peaks of opposite polarity placed in the range of $-100 \leq \Delta \lambda \leq+100 \mathrm{~m} \AA$. The nearest $\partial I / \partial \lambda$ parameter (which is shown on the Figure by a dashed line) corresponds to $\gamma=0^{\circ}$ and $\Delta \lambda_{H}=10 \mathrm{~m} \AA$. For FeI 5434.527, the relation between the magnetic field strength $B$ and the Zeeman splitting $\Delta \lambda_{H}$ is as follows: $=5.18 \times 10^{6}$ $\Delta \lambda_{H}$ (where $B$ is given in $\mathrm{G}$, and $\Delta \lambda_{H}$ is in $\AA$ ), for $\Delta \lambda_{H}=10 \mathrm{~m} \AA$ we have $B=51.8 \mathrm{kG}$.

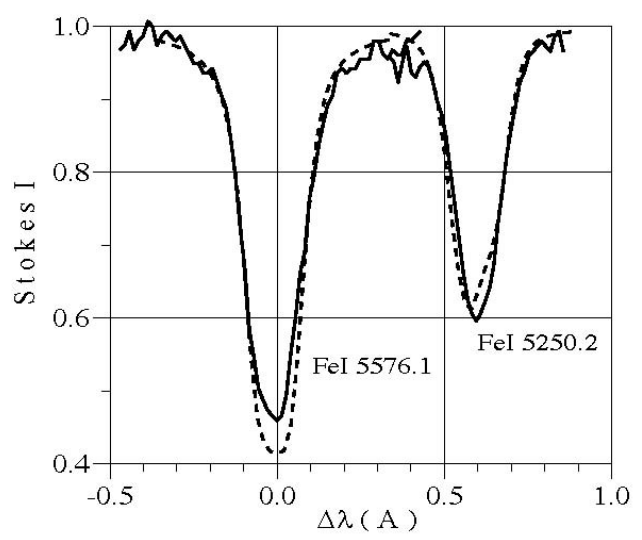

Fig. 7. Comparison of the observed (solid lines) and theoretical (dashed lines) Stokes $I$ profiles for the flare, for $L=10$ (see above Fig. 5).

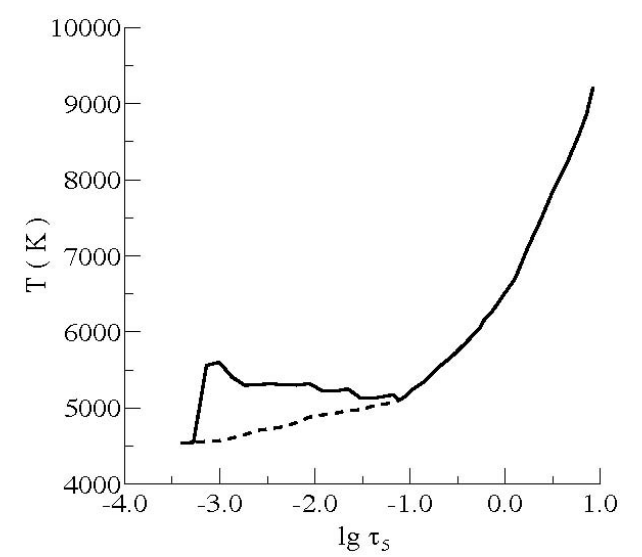

Fig. 8. Temperature $T$ vs. optical depth $\tau_{5}$ in the photospheric layers of the flare (solid line - the flare, circles undisturbed atmosphere [30]), for $L=10$.

It is interesting to compare this estimation with the data of direct measurements of the bisector splitting $\Delta \lambda_{B}$ of emissive peaks in $I \pm V$ profiles (Fig. 3). Note, that the method of bisector splitting was discussed in detail in paper [21] for the study of other flares. As to the flare of 28 October 2003, it was found, that $\Delta \lambda_{B} \approx 17 \mathrm{~m} \AA$, which means $\Delta \lambda_{H} \approx 8.5 \mathrm{~m} \AA$ (for $\gamma=0^{\circ}$ ), or $B \approx 44 \mathrm{kG}$. Thus, both estimations differ by about $12 \%$. This difference, in the first approximation, can be taken as the error level of our interpretation.

The observed Stokes $V$ peak separation $\Delta \lambda_{V}$ is about $60 \mathrm{~m} \AA$. This means, as it was mentioned above, that true half-width $\Delta \lambda_{1 / 2}$ of splitted emissive peaks is about
$60 \mathrm{~m} \AA$ too. For comparison, it is useful to remember that the half-width of the undisturbed Fraunhofer profile of this line is about $200 \mathrm{~m} \AA$. That is, the emission peaks are more than 3 times narrower than the Fraunhofer profile of the same line.

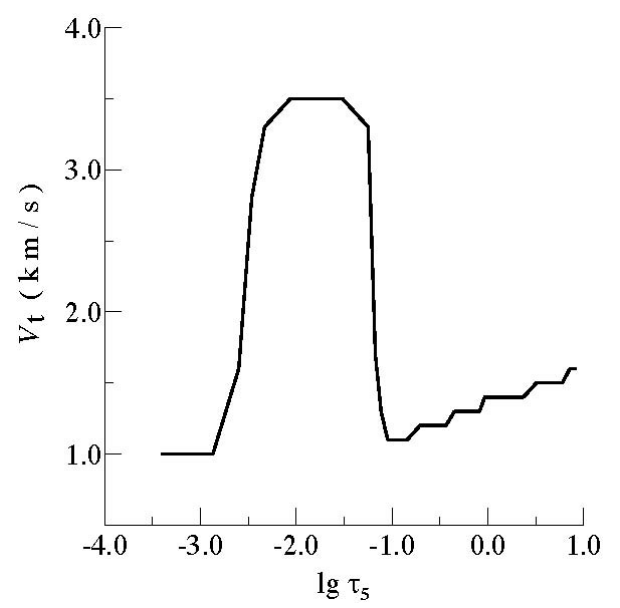

Fig. 9. Turbulent velocity $v_{\mathrm{t}}$ vs. optical depth $\tau_{5}$ in the photospheric layers of the flare for $L=10$.

Earlier a similar effect of the half-width of the flare emission in FeI 5434.5 was discussed by Lozitsky et al. [22]. They obtained a correlation coefficient of about 0.7 between the observed emission width and the relative intensity of this emission. It is important to note that if the regression line (see Fig. 1 in [22]) is continued to zero intensities, then we have a half-width of about $30 \mathrm{~m} \AA$. But $30 \mathrm{~m} \AA$ is the half-width of the instrumental profile of the Echelle spectrograph. This means that the actual emission widths, in fact, are very small. In this connection, Lozitsky et al. [23] made a correction of the data taking into account the instrumental broadening of the spectrum. It turned out that the actual width of the flare emissions in the FeI 5434.5 line can be about $10 \mathrm{~m} \AA$. Such narrow widths correspond to a very low kinetic temperature, only a few hundred degrees. This means that a very strong magnetic field can significantly lower the temperature, figuratively speaking, "freeze" the plasma. Let us remember the well known examples of the cooling effect of the magnetic field, namely sunspots and prominences. In the first case, the temperature drops about 1.7 times, whereas in the second case it decreases by 2 orders of magnitude. But it remains unclear how low the temperature falls in sub-telescopic structures with especially strong magnetic fields. This is an important issue for future studies.

\section{SEMI-EMPIRICAL MODEL}

A semi-empirical model of the flare was build with the PANDORA code, which allows to determine the magnetic field and thermodynamical conditions on both photospheric and chromospheric levels using non-LTE approximation. This code was made by E. A. Baranovsky (with 
the help by E. Malanushenko) using the algorithm published in the paper by Avrett and Loeser [24].

The main physical parameters for photospheric layers were obtained from FeI 5576.1 and FeI 5250.2 lines (Fig. 7). The following parameters were varied for the best fit of the theoretical and observed profiles: temperature $T$, turbulent velocities $v_{\mathrm{t}}$ and magnetic field $B$. The values of $T$ and $v_{\mathrm{t}}$ were determined by FeI 5576.1 line, and magnetic field $B-$ by FeI 5250.2 , from halfwidth of Stokes $I$ profile. Also, it was assumed that the the longitudinal velocity $v_{\|}$equals zero.

It was found with this approach that the magnetic field in the photosphere is $B=1000-1200 \mathrm{G}$. The semiempirical model of the thermodynamic conditions has almost the same temperature $T$ as an undisturbed atmosphere, but for $\lg \tau_{5}>-1$ (Fig. 8). For $\lg \tau_{5}<-1$, temperature in the flare is higher than in an undisturbed atmosphere, and the peak of this rise corresponds to $\lg \tau_{5} \approx-3$, where $\Delta T \approx 1000 \mathrm{~K}$. These results confirm the conclusions presented earlier in papers $[3,9,11]$. The turbulent velocity $v_{\mathrm{t}}$ in range from $\lg \tau_{5}=1$ to $\lg \tau_{5}=-1$ is almost the same as in an undisturbed atmosphere, but it has a sharp increase in the range from $\lg \tau_{5}=-1$ to $\lg \tau_{5}=-3$, where $v_{\mathrm{t}}$ reaches about $3.5 \mathrm{~km} / \mathrm{s}$ (Fig. 9).

\section{DISCUSSION}

Of significant interest is the "violet" Doppler shift of the emission peaks in the core of FeI 5434.5 (Figs. 3 and 4). Its value is $35-40 \mathrm{~m} \AA$, which corresponds to about $1.8-2.0 \mathrm{~km} / \mathrm{s}$ of the Doppler velocity. A similar effect the lifting of plasma with the velocities from 1.7 to 3.1 $\mathrm{km} / \mathrm{s}$ - was found also in the umbra of great sunspots, in spatially unresolved magnetic elements with strength about $8 \mathrm{kG}[12,25]$. The methodical problems of magnetic field measurements in the sunspot umbra were discussed in detail in the paper by Lozitska et al. [26].

This lifting of plasma clarifies somewhat the question, what is the source of the extremely strong magnetic field in the flare. Indeed, it is highly unlikely that this field formed somehow at the same height, where it was observed. Indeed, as it was mentioned in [27], in the upper photosphere gas pressure can hold a magnetic field strength of up to $500 \mathrm{G}$. But the gas pressure increases rapidly under the photosphere, and in some range of depths it should be sufficient for the magnetic field concentration on the level of $\sim 10^{4} \mathrm{G}$. This suggests that the finally shaped magnetic structures are lifted on the Sun surface [28].

A similar hypothesis concerning non-flare active regions was expressed previously by Piddinghton [29]. He assumed that at a certain depth of the Sun, magnetic "trees" can arise of many hundreds or thousands of twisted magnetic flux-ropes, the magnetic fields in each rope containing about $4 \mathrm{kG}$. The rise of the magnetic "tree" on the surface gives an observational manifestation of the active region with sunspots, pores, faculae, etc. As we can see, the above-presented data are consis- tent with this hypothesis, except that the real magnetic field strength in the twisted magnetic ropes may be an order of magnitude higher than it was assumed by Piddington [29].

\section{CONCLUSIONS}

Magnetic fields at the photospheric layers of the solar proton flare of October 28, 2003 of X17.2/4B class, as it follows from the observations made in nine spectral lines of FeI and FeII, had the following peculiarities:

(a) the effective magnetic field $B_{\text {eff }}$ varied with height, from $0-200 \mathrm{G}$ in the middle photosphere to $1000-$ $1200 \mathrm{G}$ in the upper photosphere;

(b) in the same location in the picture plane, inside the aperture area of about $3 \mathrm{Mm}^{2}$, spatially unresolved structures with a "superstrong" magnetic field (SMF) of about 25-50 kG probably had existed, which is evident by the weak spectral splitting (10-20 mA) of emission peaks in FeI 5434.527 line with a very low Lande factor, $g_{\text {eff }}=-0.014$;

(c) the magnetic polarity in SMF places was $N$, i.e. the opposite to the $S$ polarity derived from other photospheric lines with larger Lande factors $\left(g_{\text {eff }}=0.9-3.0\right)$;

(d) in the areas of SMF, a lifting of plasma was observed with the velocity of about $2 \mathrm{~km} / \mathrm{s}$; a similar effect was absent from areas with weaker fields.

These results are indirect evidence that the SMF structures form in sub-photospheric layers, and they lift on the Sun's surface in the ready stage, which is qualitatively consistents with Piddinhton's hypothesis [29].

A semi-empirical model of the flare was build with the PANDORA code, which allows to determine the magnetic field and thermodynamical conditions on both photospheric and chromospheric levels using non-LTE approximation. It was found that the magnetic field in the middle photosphere was 1000-1200 G. The temperature in the flare increased up to $1000 \mathrm{~K}$ for $\lg \tau_{5} \approx-3$. This result is similar to the conclusions presented earlier in papers $[3,9,11]$. The turbulent velocity $v_{\mathrm{t}}$ is almost the same as in an undisturbed atmosphere, but in the range from $\lg \tau_{5}=1$ to $\lg \tau_{5}=-1$; from $\lg \tau_{5}=-1$ to $\lg \tau_{5}=-3$ a sharp increase in $v_{\mathrm{t}}$ was found, where $v_{\mathrm{t}}$ reaches about $3.5 \mathrm{~km} / \mathrm{s}$ (Fig. 9).

\section{Acknowledgements}

The authors are obliged cordially to the anonymous referees for their useful critical notes, comments and proposals. This study was funded by the Taras Shevchenko National University of Kyiv, project No. 16БФ023-01, and by the Crimea Astrophysical Observatory, project "Physical relationships of solar formations", grant РФФИ № 16-42-910467 p-аэ. 
[1] E. R. Priest, T. D. Forbes, Astron. Astrophys. Rev. 10, 313 (2002).

[2] S. Tsuneta et. al, Solar Phys. 249, 167 (2008).

[3] V. G. Lozitsky, E. A. Baranovsky, N. I. Lozitska, U. M. Leiko, Solar Phys. 191, 171 (2000).

[4] V. G. Lozitsky, Kinem. Phys. Celest. Bodies 9, 18 (1993).

[5] V. G. Lozitsky, Kinem. Phys. Celest. Bodies 14, 401 (1998).

[6] V. G. Lozitsky, J. Phys. Stud. 13, 2903 (2009).

[7] E. V. Kurochka, V. G. Lozitsky, Kinem. Phys. Celest. Bodies, Suppl. № 5, 143 (2005).

[8] V. I. Abramenko, E. A. Baranovsky, Solar Phys. 220, 81 (2004).

[9] E. S. Andriets, N. N. Kondrashova, E. V. Kurochka, V. G. Lozitsky, Bull. Crimean Astrophys. Obs. 108, 1 (2012).

[10] E. S. Andriets, N. N. Kondrashova, Adv. Space Res. 55, 871 (2015).

[11] E. V. Kurochka, V. G. Lozitsky, O. B. Osyka, Kinem. Phys. Celest. Bodies, 24, 308 (2008).

[12] V. G. Lozitsky, Adv. Space Res. 57, 398 (2016).

[13] I. S. Laba, Kinem. Phys. Celest. Bodies 23, 51 (2007).

[14] http://www.spaceweather.com/solarflares /topflares.html.

[15] V. G. Lozitsky, Astron. Lett. 35, 136 (2009).
[16] E. A. Baranovsky, V. G. Lozitsky, V. P. Tarashchuk, Kinem. Phys. Celest. Bodies 25, 373 (2009).

[17] Ch. E. Moore, M. G. J. Minnaert, J. Houtgast, Nat. Bureau Stand. Monogr. 61, 349 (1966).

[18] E. N. Zemanek, A. P. Stefanov, Vestnik Kiev Univ., Ser. Astron. 18, 20 (1976).

[19] N. I. Lozitskaya, V. G. Lozitskii, A. A. Solov'ev, Kinem. Fiz. Nebesn. Tel 7, 40 (1991).

[20] H. W. Babcock, Astrophys. J. 118, 387 (1953).

[21] V. G. Lozitsky, J. Staude, J. Astrophys. Astron. 29, 387 (2008).

[22] V. G. Lozitsky, M. Yu. Gordovsky, N. I. Lozitska, E. Golbraikh, Kinem. Phys. Celest. Bodies, Suppl. № 3, 449 (2000).

[23] V. G. Lozitsky, N. I. Lozitska, M. Yu. Gordovskyy Visnyk Kyiv. Univ., Ser. Astron. 35, 17 (1999).

[24] E. H. Avrett, R. Loeser, SAO, Special Report 303 (1969).

[25] V. G. Lozitsky, Adv. Space Res. 59, 1416 (2017).

[26] N. I. Lozitska et al., Adv. Space Res. 55, 897 (2015).

[27] V. G. Lozitsky, Intern. J. Astron. Astrophys. 1, 147 (2011).

[28] V. G. Lozitsky, Adv. Space Res. 55, 958 (2015).

[29] J. H. Piddington, Astrophys. Space Sci. 55, 401 (1978).

[30] H. Holweger, E.H. Müller, Solar Phys. 39, 19 (1974).

\title{
МАГНІТНІ ПОЛЯ Й ТЕРМОДИНАМІЧНІ УМОВИ У ФОТОСФЕРНИХ ШАРАХ СОНЯЧНОГО СПАЛАХУ 28 ЖОВТНЯ 2003 РОКУ БАЛУ Х17.2/4В
}

\author{
В. Г. Лозицький ${ }^{1}$, Е. О. Барановський ${ }^{2}$, Н. Й. Лозицька ${ }^{1}$, В. П. Таращук ${ }^{2}$ \\ ${ }^{1}$ Астрономічна обсерваторія Київського начіонального університету \\ імені Тараса Шевченка, Київ, Україна \\ ${ }^{2}$ Кримсъка астрофізична обсерваторія, Научний, Крим \\ e-mail: lozitsky@observ.univ.kiev.ua
}

Подано результати вимірювань магнітного поля й дані напівемпіричного моделювання для винятково потужного сонячного спалаху 28 жовтня 2003 р. балу X17.2/4B, який виник в активній області NOAA 0486. Спостерігали спалах на ешельному спектрографі горизонтального сонячного телескопа Астрономічної обсерваторії Київського національного університету імені Тараса Шевченка. Проаналізовані дані стосуються фази максимуму спалаху та ділянки фотосфери за межами сонячних плям.

Дев'ять спектральних ліній відібрано для аналізу, включаючи такі добре відомі лінії, як FeI 5247.052, 5250.212, 6301.515, 6302.507 ^ тощо. Три “немагнітні" лінії FeI 5123.723, 5434.527 і $5576.097 \AA$ були також вивчені (їх ефективні фактори Ланде, фактично, $-0.013,-0.014$ і -0.012 відповідно).

Напруженість магнітного поля вимірювали трьома методами: (1) за розщепленням "центрів ваги" профілів $I \pm V,(2)$ за амплітудою параметра Стокса $V$ в наближенні “слабкого поля", і (3) використовуючи програмний код PANDORA, який дає змогу побудувати напівемпіричну модель спалаху.

Виявлено, що в найяскравішому місці спалаху ефективне магнітне поле $B_{\text {eff }}$ було 0-200 G на рівні середньої фотосфери (лінії FeI 6302.5 та 5250.2) 600-1200 G у верхній фотосфері і зоні температурного мінімуму (лінії FeII 4923.9 та 5234.6), і мало полярність $S$.

У ядрі лінї FeI 5434.527 виявлено слабке розщеплення її емісійних піків, його величина 10-20 mÅ. Якщо це розщеплення трактувати як прояв ефекту Зеємана, то відповідне магнітне поле - близько 25-50 kG. Магнітна полярність цього "надпотужного" поля має бути $N$, тобто протилежна до полярностей, знайдених по інших лініях FeI з більшими факторами Ланде.

Напівемпірична модель спалаху побудована за допомогою коду PANDORA, який дозволяє визначити магнітні поля й термодинамічні умови на фотосферному й хромосферному рівнях у не-ЛТР наближенні. Знайдено, що магнітне поле в середній фотосфері було 1000-1200 G. Температура у спалаху зростала приблизно на $1000 \mathrm{~K}$ при $\lg \tau_{5} \approx-3$. Турбулентна швидкість $v_{\mathrm{t}} \epsilon$ майже такою ж, як в незбуреній атмосфері, але лише в діапазоні від $\lg \tau_{5}=1$ до $\lg \tau_{5}=-1$; в інтервалі від $\lg \tau_{5}=-1$ до $\lg \tau_{5}=-3$ відмічено різке зростання параметра $v_{\mathrm{t}}$, де його величина досягала приблизно $3.5 \mathrm{kм} / \mathrm{c}$. 